\title{
Synthesis and functionalization of coumarin-containing copolymers for second order optical nonlinearities
}

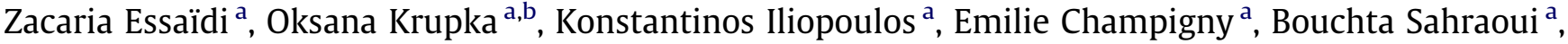 \\ Marc Sallé ${ }^{\mathrm{a}}$, Denis Gindre ${ }^{\mathrm{a}, *}$ \\ a LUNAM University, University of Angers, CNRS UMR 6200, Laboratory MOLTECH-Anjou, 2 bd Lavoisier, 49045 ANGERS cedex, France \\ ${ }^{\mathrm{b}}$ Kyiv Taras Shevchenko National University, Department of Chemistry, UA-01033 Kiev, Ukraine
}

\section{A R T I C L E I N F O}

\section{Article history:}

Received 18 August 2012

Received in revised form 13 October 2012

Accepted 15 October 2012

Available online 29 November 2012

\section{Keywords:}

Copolymers

Photoinduced dimerization

Corona poling

SHG

\begin{abstract}
A B S T R A C T
The second-order nonlinear optical properties of photocross-linkable coumarin-based copolymers were investigated using the optical second harmonic generation (SHG) with the Maker fringes technique. High quality and transparent spin-deposited thin films of various methacrylic copolymers containing 4-methylcoumarin pendant chromophores were prepared and the coumarin units were ordered and oriented by the corona poling technique. Nonlinear optical investigations were performed using a picosecond Qswitched Nd:YAG laser working at the fundamental wavelength $(\lambda=1064 \mathrm{~nm})$ and the second order nonlinear optical susceptibilities of the functionalized polymers were determined. The samples were irradiated using two wavelengths $(\lambda=254 \mathrm{~nm}$ and $\lambda>300 \mathrm{~nm})$ promoting the reversible photo-induced dimerisation of coumarin moieties within the film. The latter is shown to have a significant impact on the nonlinear optical response of the corresponding material. A large SHG response of photocross-linkable coumarin-based copolymers is obtained.
\end{abstract}

(c) 2012 Elsevier B.V. All rights reserved.

\section{Introduction}

Within the last decade various types of nonlinear optical (NLO) polymers were synthesized and functionalized with different active chromophores grafted in their side chain: polymethylmethacrylates, polyalkylviniletheres, polystyrenes, polyimides, polyacrylamides and many more [1-3]. The photochemical properties of such polymers can be advantageously addressed for photonics and nonlinear optics applications [4-7]. In addition, the spatial organization of the active side chain residues along the polymeric backbone is of critical importance regarding mechanical and structural properties of the material.

In this context, coumarin derivatives are suitable candidates for NLO investigations. More over such compounds are already wellknown for their photochemical and photophysical properties. In particular they can undergo a reversible photoinduced cyclodimerisation upon irradiation at $\lambda>300 \mathrm{~nm}$, leading to cyclobutanebased dimers with four possible isomeric configurations (Scheme 1) [8-13].

Therefore, the resulting systems are considerably, both structurally and electronically, altered. A consequence at the polymeric scale is that pendant groups can give rise to cross-linked polymers upon exposure to a $\lambda>300 \mathrm{~nm}$ source [14]. Therefore, polymers

\footnotetext{
* Corresponding author.

E-mail address: denis.gindre@univ-angers.fr (D. Gindre).
}

with coumarin fragments have been used in many fields such as photoalignment of liquid crystalline molecules [9,15], photoactive surface application [16], electroluminescence [17], fluorescence materials and laser dyes [18]. Our group also described recently the reversible two-photon optical data storage of coumarin-based copolymers [19].

In the present work we report the results obtained from thin films derived from various methacrylic polymers functionalized with 4-methyl coumarin side-groups as NLO active units. Co-polymers of various molecular compositions (monomers ratio) and involving 4-methyl coumarin-based monomers with linkers of different lengths, have been systematically studied. The corresponding thin films have been subjected to corona-poling and to suitable irradiation leading to two distinctive states (Scheme 1), Pm (incorporating "free" 4-methyl coumarin units) and $\mathbf{P m}^{\prime}$ (photocross-linked state). Pm and $\mathbf{P m}^{\prime}$ were characterized by UV-visible spectroscopy and their second order NLO response was measured by the Second Harmonic Generation (SHG) Maker fringes technique at $\lambda=1064 \mathrm{~nm}$.

\section{Experimental section}

\subsection{Chemicals}

$\mathrm{N}, \mathrm{N}$-Dimethylformamide (DMF) was vacuum-distilled off from calcium hydride just prior to use. 2,2-Azobis(isobutyronitrile) 
<smiles>CCCCCCCCc1ccc2c(C)cc(=O)oc2c1</smiles>

Pm

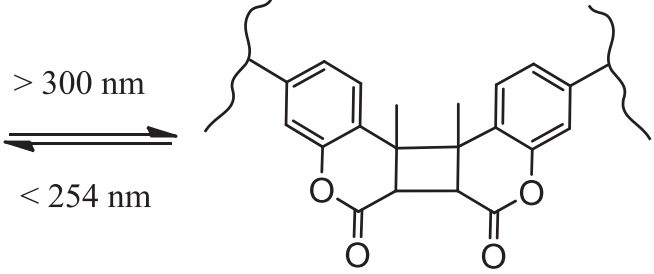

Pm'

Scheme 1.

(AIBN) was recrystallized twice from absolute methanol. Methylmethacrylate (MMA) and butylmethacrylate (BMA) are commercially available and were washed with aq $\mathrm{NaOH}$ to remove inhibitors, dried with $\mathrm{CaCl}_{2}$ under nitrogen atmosphere at reduced pressure. All other reagents and solvents were commercially available and used as received.

\subsection{Apparatus}

${ }^{1} \mathrm{H}$ NMR (500 MHz) spectra were recorded by a "Bruker Advance DRX-500" spectrometer using DMSO- $\mathrm{d}_{6}$ or $\mathrm{CDCl}_{3}$ as solvent. Chemical shifts are in ppm from the internal standard tetramethylsilane.

$U V-V I S$ measurements were performed at room temperature either in solutions in a quartz liquid cell, or as thin films deposited on glass substrates, with a Perkin-Elmer UV/VIS/NIR Lambda 19 spectrometer.

Differential scanning calorimetry: A Q20 model DSC (TA Instruments), with a continuous $N_{2}$ purge was used to determine the glass and phase transition temperatures $\left(T_{\mathrm{g}}\right)$ of all polymers. Two scans were run at a heating rate of $10^{\circ} \mathrm{C} / \mathrm{min}$ up to $200{ }^{\circ} \mathrm{C}$, followed by a cooling to $20^{\circ} \mathrm{C}$, giving the values of $T_{\mathrm{g}}$.

Gel permeation chromatography: The molecular weights of all polymers were evaluated with Spectra SYSTEM RI-150 and Spectra SYSTEM UV2000 detectors. Spectra SYSTEM AS1000 autosampler, with a guard column (Polymer Laboratories, PL gel $5 \mu \mathrm{m}$ Guard, $50 \times 7.5 \mathrm{~mm}$ ) followed by 2 columns (Polymer Laboratories, $2 \mathrm{PL}$ gel $5 \mu \mathrm{m}$ MIXED-D columns, $2 \times 300 \times 7.5 \mathrm{~mm}$ ). The eluent used is THF at a flow rate of $1 \mathrm{ml} / \mathrm{min}$ at $35^{\circ} \mathrm{C}$. Polystyrene standards $\left(580-4.83 \times 10^{3} \mathrm{~g} / \mathrm{mol}\right)$ were used for calibration.

MS spectra were recorded on a Trace DSQ (Thermo Electron Corp.) GC/MS mass spectrometer.

\subsection{Synthesis}

Methacrylic monomers based on 4-methylcoumarin 1, 3 were obtained by adapting described procedures [20,21] (Scheme 2). Methacryloyl chloride was reacted with the suitable hydroxy derivative of 4-methylcoumarin in the presence of triethylamine.

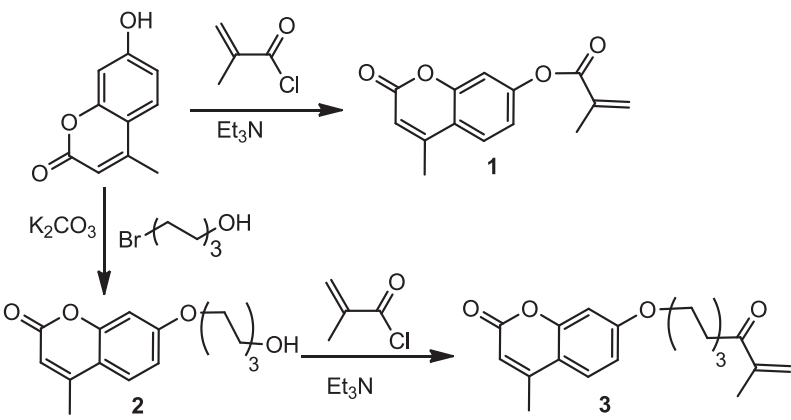

Scheme 2 .
The hydroxylated intermediate $\mathbf{2}$ was synthesized as described by alkylation of 7-hydroxy-4-methylcoumarin.

\subsubsection{7-Methacryloyloxy-4-methylcoumarin (1)}

Recrystallization from ethanol gave colorless plates m.p. $177^{\circ} \mathrm{C}$, 85\%. ${ }^{1} \mathrm{H}$ NMR (500 MHz, $\left.\mathrm{CDCl}_{3}\right): \delta 2.05\left(\mathrm{~s}, 3 \mathrm{H},-\mathrm{CH}_{3}\right), 2.41(\mathrm{~s}, 3 \mathrm{H}$, $\left.-\mathrm{CH}_{3}\right), 5.80\left(\mathrm{~s}, 1 \mathrm{H}, \mathrm{CH}_{2}=\right), 6.23(\mathrm{~d}, 1 \mathrm{H},=\mathrm{CH}-\mathrm{C}(\mathrm{O})-), 6.35(\mathrm{~s}, 1 \mathrm{H}$, $\mathrm{CH}_{2}=$ ), 7.09 (t, 2H, Ar-H), 7.60 (d, 1H, Ar-H). MS, m/z: $244[\mathrm{M}]^{+}$.

\subsubsection{7-[(6-Hydroxyhexyl)oxy]-4-methylcoumarin (2)}

The crude product was purified by column chromatography on silica gel (hexane: ethylacetate, 4:6), and affords white crystals m.p. 81-82 ${ }^{\circ} \mathrm{C}, 82 \% .{ }^{1} \mathrm{H}$ NMR $\left(500 \mathrm{MHz}, \mathrm{CDCl}_{3}\right): \delta 1.40-1.85(\mathrm{~m}$, $\left.8 \mathrm{H},-\mathrm{CH}_{2} \mathrm{CH}_{2} \mathrm{CH}_{2} \mathrm{CH}_{2}-\right), 2.38\left(\mathrm{~s}, 3 \mathrm{H},-\mathrm{CH}_{3}\right), 3.66\left(\mathrm{t}, 2 \mathrm{H},-\mathrm{CH}_{2} \mathrm{OH}\right)$, $4.00\left(\mathrm{t}, 2 \mathrm{H},-\mathrm{CH}_{2}-\mathrm{OAr}\right), 6.17(\mathrm{~d}, 1 \mathrm{H},=\mathrm{CH}-\mathrm{C}(\mathrm{O})-), 6.81(\mathrm{t}, 2 \mathrm{H}$, $\mathrm{Ar}-\mathbf{H}), 7.48$ (d, 1H, Ar-H). MS, m/z: $276[\mathrm{M}]^{+}$.

\subsubsection{7-[[[6-(Methacryloyl)oxy]hexyl]oxy]-4-methylcoumarin (3)}

7-[(6-Hydroxyhexyl)oxy]-4-methylcoumarin (2) (1.33 g; $0.0048 \mathrm{~mol}$ ) was dissolved in dry methylene chloride $(30 \mathrm{ml})$. The reaction mixture was kept at $0-5{ }^{\circ} \mathrm{C}$ then triethylamine $(0.68 \mathrm{ml}$; $0.005 \mathrm{~mol})$ and methacryloyl chloride $(0.48 \mathrm{ml} ; 0.005 \mathrm{~mol})$ were added gradually. The solution was refluxed for $4 \mathrm{~h}$ and washed (1 M hydrochloric acid, 10\% sodium hydroxide) and dried over anhydrous magnesium sulfate. The crude oil was purified by column chromatography on silica gel using methylene chloride, yield 54\%. ${ }^{1} \mathrm{H}$ NMR (500 MHz, $\left.\mathrm{CDCl}_{3}\right): \delta 1.45-1.85\left(\mathrm{~m}, 8 \mathrm{H},-\mathrm{CH}_{2} \mathrm{CH}_{2} \mathrm{CH}_{2-}\right.$ $\left.\mathrm{CH}_{2}-\right), 1.93\left(\mathrm{~s}, 3 \mathrm{H}, \mathrm{H}_{2} \mathrm{C}=\mathrm{C}\left(\mathrm{CH}_{3}\right)-\right), 2.38\left(\mathrm{~s}, 3 \mathrm{H},-\mathrm{CH}_{3}\right), 4.00(\mathrm{t}, 2 \mathrm{H}$, $\left.-\mathrm{CH}_{2}-\mathrm{OAr}\right), 4.15\left(\mathrm{t}, 2 \mathrm{H},-\mathrm{CH}_{2}-\mathrm{O}-\mathrm{C}(\mathrm{O})-\right), 5.54\left(\mathrm{~s}, 1 \mathrm{H}, \mathrm{CH}_{2}=\right), 6.08$ $\left(\mathrm{s}, 1 \mathrm{H}, \mathrm{CH}_{2}=\right), 6.10(\mathrm{~d}, 1 \mathrm{H},=\mathrm{CH}-\mathrm{C}(\mathrm{O})-), 6.77-6.83(\mathrm{~m}, 2 \mathrm{H}, \mathrm{Ar}-\mathbf{H})$, $7.45(\mathrm{~d}, 1 \mathrm{H}, \mathrm{Ar}-\mathrm{H}) . \mathrm{MS}, \mathrm{m} / z: 344[\mathrm{M}]^{+}$.

\subsection{Synthesis of copolymers}

The synthesis of copolymers Pm1-5 (Scheme 3) based on the methacrylic monomers (1 or $\mathbf{3}$ ) on one hand and methylmethacrylate (MMA) or butylmethacrylate (BMA) on the other hand, was conducted in $10 \%$ DMF solution with AIBN as radical initiator at $80{ }^{\circ} \mathrm{C}$ (argon atmosphere). The mixture was degassed with repeated freeze and thaw cycles and then heated for $24 \mathrm{~h}$. The resulting viscous solution was added into methanol to precipitate polymeric materials. The precipitation was repeated from DMF into methanol to give purified polymers. The copolymerization ratio was calculated on the basis of the integration ratio of ${ }^{1} \mathrm{H}$ NMR signals.

The polymeric structures, as well as the respective composition in both monomers ( $n / m$ ratio), were confirmed by ${ }^{1} \mathrm{H}$ NMR spectra. This ratio is in reasonable accordance with the initial amounts of monomers which were introduced (Table 1). Nevertheless, as expected from less hindered monomers, the BMA or MMA motifs are found in slight excess in the final composition of the polymers.

The glass transition temperatures $\left(T_{\mathrm{g}}\right)$ of the polymers are shown in Table 1 . As expected, a higher ratio in coumarin motif re- 

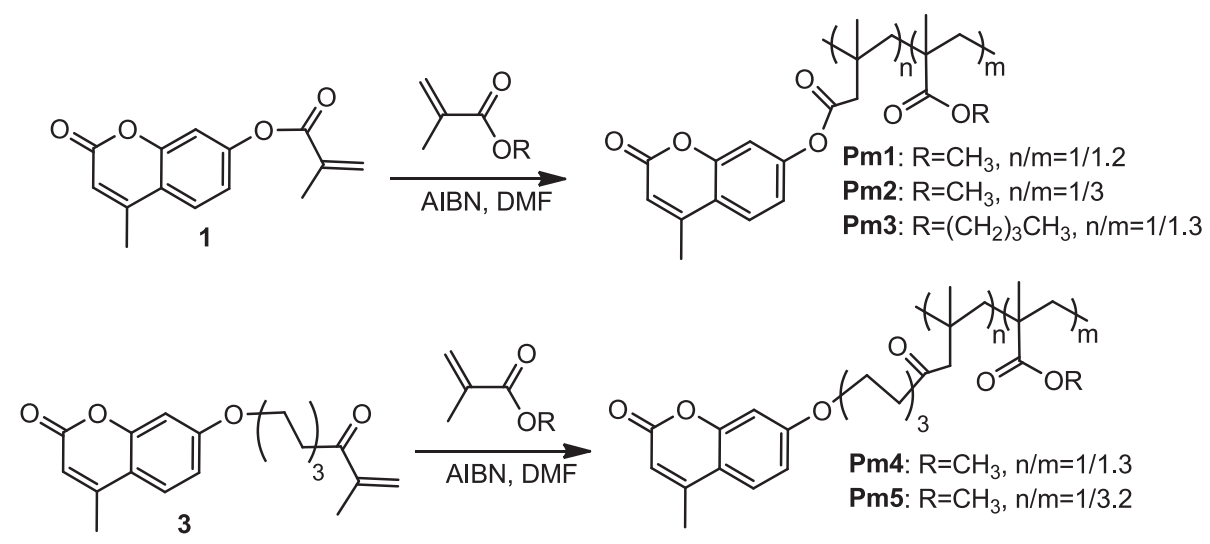

Scheme 3.

Table 1

Copolymers from radical polymerization of $10 \%$ methacrylic monomers in DMF at $80^{\circ} \mathrm{C}$ (argon atmosphere, initiator - AIBN 1\%).

\begin{tabular}{llllll}
\hline Polymer & Monomers mole ratio $^{\mathrm{a}}$ & $n / m^{\mathrm{b}}$ & $\mathrm{Mw}^{\mathrm{c}}$ & $\mathrm{Mw} / \mathrm{Mn}^{\mathrm{c}}$ & $T_{\mathrm{g}}{ }^{\mathrm{d}} \mathrm{T}_{\mathrm{g}}\left({ }^{\circ} \mathrm{C}\right)^{\mathrm{d}}$ \\
\hline Pm1 & $1: 1$ & $1: 1.2$ & 34,000 & 1.6 & 143 \\
Pm2 & $1: 3$ & $1: 3.0$ & 33,000 & 1.7 & 110 \\
Pm3 & $1: 1$ & $1: 1.3$ & 36,000 & 1.9 & 81 \\
Pm4 & $1: 1$ & $1: 1.3$ & 25,000 & 1.8 & 40 \\
Pm5 & $1: 3$ & $1: 3.2$ & 36,600 & 2 & 47 \\
\hline
\end{tabular}

a The ratio is given relatively to the coumarin-based monomer.

b Determined by ${ }^{1} \mathrm{H}$ NMR integration.

c Measured by GPC.

d Measured by DSC.

sults in a higher $T_{\mathrm{g}}$ when MMA is used (Pm1 vs Pm2). Also introduction of conformationally flexible alkyl chains within the coumarin chromophore and/or in the methacrylate comonomer (BMA) tend to decrease $T_{\mathrm{g}}$ (Pm3 vs Pm1; Pm4 vs Pm1; Pm5 vs Pm2). The copolymers molecular weights are in the limit $25,000-36,600$ and polydispersity indices are $1.6-2$ as determined by GPC (Table 1 ).

\subsection{Thin films processing and thickness measurement}

The spin-coating deposition technique was used to produce thin films of 4-methyl coumarin functionalized polymers with a controlled thickness, on glass slides BK7. Polymer films were spincoated at $800 \mathrm{rpm}$ from a $10 \mathrm{wt} . \%$ 1,1,2-trichloroethane solution previously filtered through a $0.4 \mu \mathrm{m}$ pore size nylon syringe filter. Immediately after deposition, the thin films were dried in vacuum at $35^{\circ} \mathrm{C}$ for $5 \mathrm{~h}$ to eliminate any remaining solvent. The thickness of the thin solid films was measured with a 6 M DEKTAK profilometer and was found about $1.2 \mu \mathrm{m}$ for all samples.

\subsection{Photodimerization and photocleavage}

For the SHG experiments polymer thin films (Pm) were irradiated during $60 \mathrm{~min}$ at $20^{\circ} \mathrm{C}$ to produce the corresponding crosslinked polymers $\left(\mathbf{P m}^{\prime}\right)$ with a UV immersion lamp TQ $150 \mathrm{~W}$ (Heraeus) equipped with a filter (Duran 50, Heraeus) that cuts off wavelengths below $300 \mathrm{~nm}$. Conversely, the photocleavage of coumarin dimer (from $\mathbf{P m}$ ' to $\mathbf{P m}$ ) was achieved by using a low pressure mercury lamp TNN 15/32 (Heraeus), $15 \mathrm{~W}$ with emission wavelength spectrum at $254 \mathrm{~nm}\left(20^{\circ} \mathrm{C}, 30 \mathrm{~min}\right)$.

\subsection{Corona poling}

Various experimental techniques can be used for measuring the nonlinearities of given materials, even though each technique ad- dresses only a particular facet of the nonlinearity due to the frequency dispersion of second or third order susceptibilities. Coumarin containing polymers, being amorphous, does not exhibit second-order NLO properties. Thus, to overcome this issue, it is well established that orientation of the dipole moment in organic thin films can be performed using optical or corona poling [22,23].

The corona poling technique was used to align the chromophores and break the centrosymmetrical attribute of the investigated films. During this procedure the thin films were heated close to the glass transition temperature $T_{\mathrm{g}}$ (Table 1 ), where the motion of the chromophores can be facilitated and their orientation too. Then a high voltage of $4500 \mathrm{~V}$ was applied by means of two parallel tungsten wires positioned over the film, providing a strong electric field which leads to a homogeneous alignment of the chromophores. Last, the sample were cooled down to room temperature, while still applying the electric field in order to fix the alignment of the molecule dipole moments.

\subsection{Second-order optical nonlinearities investigations}

SHG Maker fringes measurements were performed in transmission configuration using a Q-switched Nd:YAG laser (Leopard D10) as a source of excitation, providing a fundamental wavelength at $\lambda=1064 \mathrm{~nm}$, with $16 \mathrm{ps}$ pulse duration and $10 \mathrm{~Hz}$ repetition rate. The absorption spectrum of each sample was performed before the NLO measurements and we found that the thin films were transparent in the near infrared region. For the fundamental wavelength, the intensity was about $6.5 \mathrm{GW} \mathrm{cm}^{-2}$ and we did not observe any degradation of the samples during experiments. The s-polarized beam was focused slightly behind the sample by means of a convergent lens to achieve nonlinear effects. The angular dependence of the SHG signal was probed by rotating the sample by means of a motorized rotational stage, which was automatically controlled by a computer [24]. The generated harmonic signal was firstly attenuated then filtered with a $10 \mathrm{~nm}$ narrow width interferential filter and analyzed with a polarizer in s-polarization direction before being collected by the photomultiplier tube (PMT, Model Hamamatsu R1828). The experimental setup is depicted in Fig. 1.

The obtained angular variation of the SHG intensity corresponds to the so called "Maker fringes" pattern. The setup was calibrated using $y$-cut crystalline quartz slab with second order susceptibility $\chi^{(2)}=1 \mathrm{pm} / \mathrm{V}$. The quadratic susceptibility was determined using the Jerphagnon and Kurtz model [25] in which the absorption of the sample is not taken into account:

$I_{2 \omega}=\frac{128 \pi^{3}}{c A\left(n_{2 \omega} \cos \theta_{2 \omega}\right)^{2}} t_{\omega}^{4} T_{2 \omega}^{2}\left(\chi_{\text {eff }}^{(2)}\right)^{2} I_{\omega}^{2}\left(\frac{2 \pi L}{\lambda}\right)^{2} \frac{\sin ^{2}(\Phi)}{\Phi^{2}}$ 


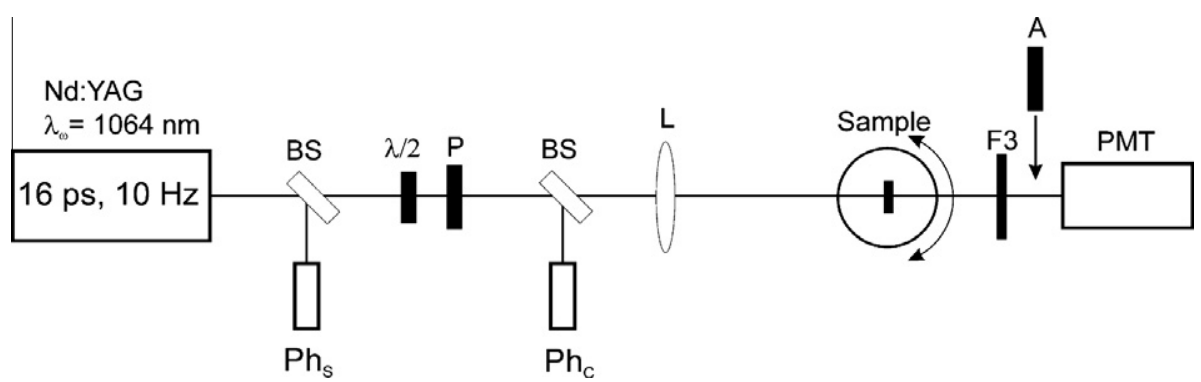

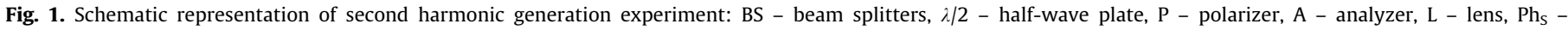
synchronization photodiode, $\mathrm{Ph}_{\mathrm{C}}$ - control photodiode, F3 - filters, PMT - photomultiplier tube.

where

$\Phi=\frac{2 \pi L}{\lambda}\left(n_{\omega} \cos \theta_{\omega}-n_{2 \omega} \cos \theta_{2 \omega}\right)$

The $t_{\omega}$ and $T_{2 \omega}$ correspond to the Fresnel transmission coefficients, $\chi_{\text {eff }}^{(2)}$ is the effective second order nonlinear susceptibility, $I_{\omega}$ is the intensity of the fundamental wave, $\lambda$ is the fundamental wavelength, $n_{\omega}, n_{2 \omega}$ are refractive indices at fundamental and at second harmonic frequencies respectively, $L$ is the thickness of the sample, $\theta_{\omega}$ and $\theta_{2 \omega}$ are the fundamental and generated harmonic refracted beams angles, respectively.

\section{Results and discussion}

\subsection{Spectroscopic studies}

The optical absorption spectra of coumarin polymers in thin films show one major absorption region (280-350 nm), assigned to the absorption of the conjugated chromophore.
Noticeably, the absorption spectra change during irradiation at $\lambda>300 \mathrm{~nm}$ light. An illustrative example is provided in the case of a polymer film Pm2 (1.2 $\mu \mathrm{m}$ thickness) as presented in Fig. 2a. The evolution of the absorption of the thin film at $312 \mathrm{~nm}$ as a function of the irradiation time is presented in Fig. 2b. During irradiation a decrease in absorbance assigned to the $\pi-\pi^{*}$ transition of the coumarin unit was observed. This decrease is due to light induced dimerization reaction into the cyclobutane ring and has been observed for all Pm systems investigated. Fig. 3a illustrates the thin film absorption spectra of $\mathbf{P} \mathbf{m}^{\prime} \mathbf{2}$, during the reverse process (from Pm2' to Pm2) under irradiation by $\lambda=254 \mathrm{~nm}$ light, while the time in Fig. $3 \mathrm{~b}$ is shown in seconds, showing that the kinetic of the photocleavage is faster than the photodimerization process.

\subsection{NLO studies}

The SHG Maker fringes setup was calibrated using a $y$-cut quartz crystal $\left(d_{11}=0.5 \mathrm{pm} / \mathrm{V}\right)$ [26]. The experimental signals were fitted theoretically according to Eqs. (1) and (2) as shown in Fig. 4. (a)

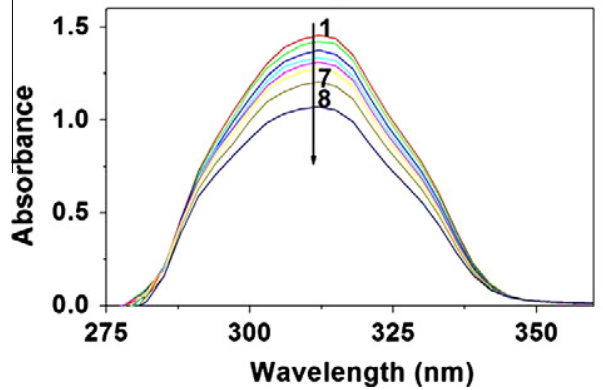

(b)

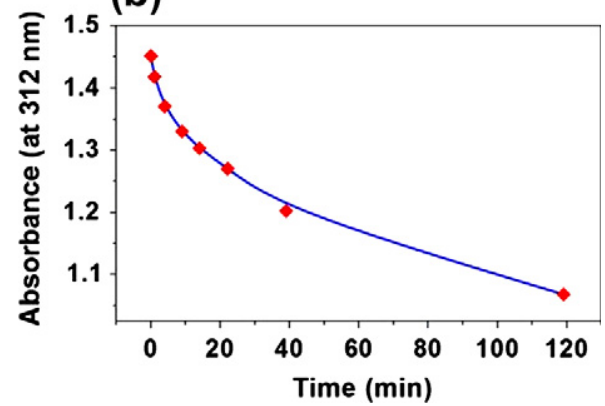

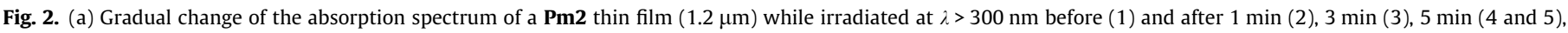
$10 \mathrm{~min}$ (6), $15 \mathrm{~min}$ (7), $80 \mathrm{~min}$ (8). (b) Absorption of a Pm2 thin film at $312 \mathrm{~nm}$, as a function of the irradiation time.

(a)

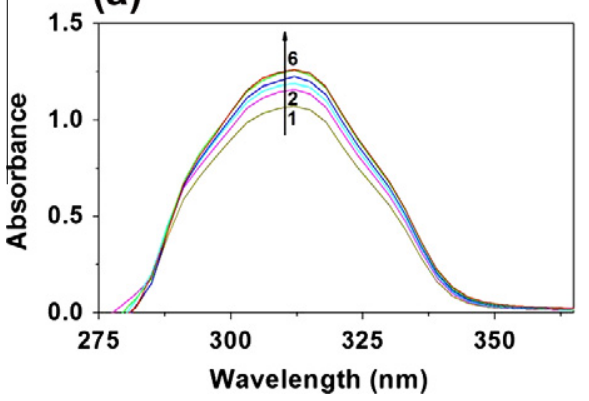

(b)

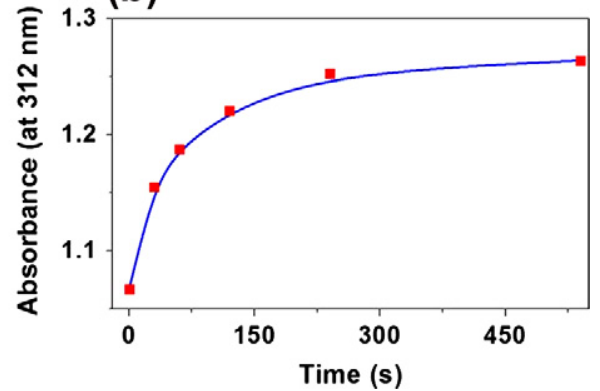

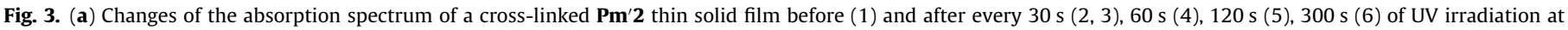
$\lambda=254 \mathrm{~nm}$; (b) changes in the absorption of film Pm2 at $312 \mathrm{~nm}$ during irradiation at $\lambda=254 \mathrm{~nm}$. 


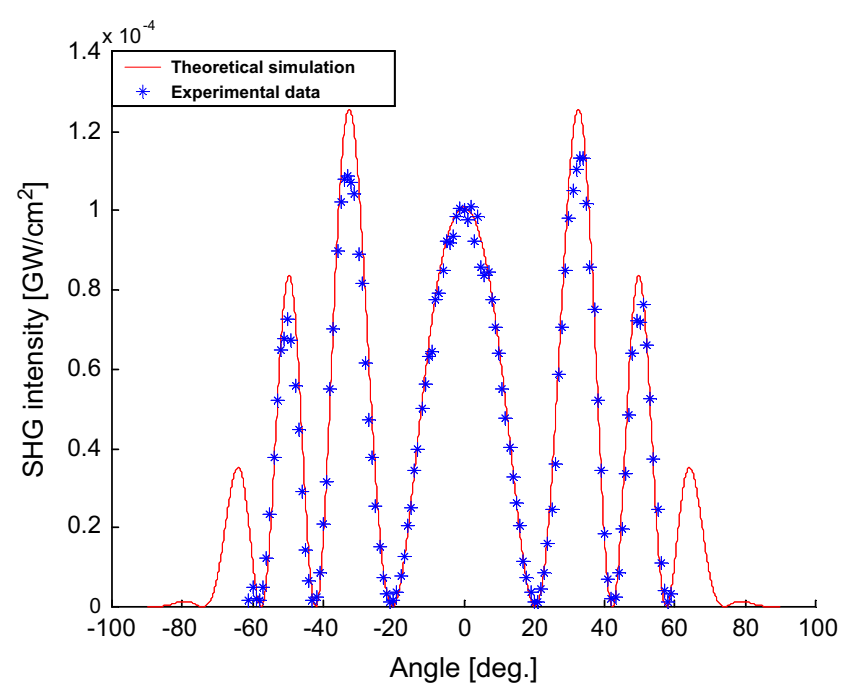

Fig. 4. Theoretical and experimental SHG Maker fringes for $y$-cut quartz slab used as reference material for calibration.

SHG measurements were carried out for all molecules before and after dimerization and photo cleavage process (UV irradiation). Typical experimental results are shown in Fig. 5a where SHG signals resulting from the $\mathbf{P m} \mathbf{2}$ to $\mathbf{P m} \mathbf{2}$ samples are reported. The data underscore that the $\mathbf{P m} / \mathbf{2}$ (sample after irradiation) exhibits lower SHG response with respect to Pm2 (non-irradiated). Similar behaviours were obtained for all the other investigated polymer/ coumarin Pm systems.

In Fig. 5b characteristic Maker fringes curves can be seen for the systems Pm1, Pm2, Pm3, obtained under the same experimental conditions in order to allow direct comparison. It should be also noted that, at least under the same conditions, the SHG was found to be negligible in the case of the systems Pm4 and Pm5. We attribute this singularity to the fact that Pm4 and Pm5 exhibit very low $T_{\mathrm{g}}$ values, so that they have a strong tendency to relax after the corona poling and the orientation of the chromophores on the film is no longer preserved.

The second order nonlinear susceptibilities $\left(\chi^{(2)}\right)$ for all investigated systems before and after irradiation at $\lambda>300 \mathrm{~nm}$ are reported in Table 2 . The determined values show that in all cases the nonlinear optical response is decreased after the photodimerization of the 4-methyl coumarin units within the film. Such observation is attributed to a modification of the molecular structure
Table 2

Second order nonlinear optical susceptibilities for polymers with a 4-methyl coumarin moiety, before (Pm1, Pm2, Pm3) and after $\left(\mathbf{P m}^{\prime} \mathbf{1}, \mathbf{P m} \mathbf{2}^{\prime} \mathbf{2}, \mathbf{P m} \mathbf{3}^{\prime}\right)$ one hour irradiation at $\lambda>300 \mathrm{~nm}$.

\begin{tabular}{ll}
\hline Sample & $\chi^{(2)} \times 10^{13}(\mathrm{~m} / \mathrm{V})$ \\
\hline $\mathbf{P m} 1$ & 7.1 \\
$\mathbf{P m} 2$ & 7.9 \\
$\mathbf{P m} 3$ & 4.1 \\
$\mathbf{P m}^{\prime} \mathbf{1}$ & 2.6 \\
$\mathbf{P m}^{\prime} \mathbf{2}$ & 5.1 \\
$\mathbf{P m}$ 3 & 1.6 \\
$y$-cut quartz plate & 10 \\
\hline
\end{tabular}

and of the resulting dipole moments of the modified chromophores. In particular the $\chi^{(2)}$ values of the $\mathbf{P m}^{\prime} \mathbf{1}, \mathbf{P m}^{\prime} \mathbf{2}, \mathbf{P m}$ '3 appear 1.6 to 2.7 times lower than for their corresponding non-irradiated Pm systems.

Further measurements were carried out in order to verify the reversible character of the nonlinear optical response during a complete photodimerization/photocleavage procedure. During this procedure, an irradiation was first carried out at $\lambda>300 \mathrm{~nm}$ (leading to the photo dimerization) and was followed by an irradiation at $\lambda=254 \mathrm{~nm}$ (inducing the photocleavage), in a way that a full $\mathbf{P m} \rightarrow \mathbf{P m}^{\prime} \rightarrow \mathbf{P m}$ cycle had been achieved. Following the SHG evolution during this process it was found that the SHG was first decreased $\left(\mathbf{P m} \rightarrow \mathbf{P m}^{\prime}\right)$ and then increased $\left(\mathbf{P m}^{\prime} \rightarrow \mathbf{P m}\right)$, retrieving the initial value of $\mathbf{P m}$. Therefore, the SHG value of the film can be tuned according to the chemical state of the coumarin-based polymer. This modification of the response emanating from different irradiation of the system can be valuable for a variety of photonic applications such as, for example, high speed [27] or high density [28] optical storage, high dynamic image storage [29].

\section{Conclusions}

The current study reports on the second order optical nonlinearities of reversibly photocross-linkable coumarin-based polymers thin films. High optical quality and transparent spindeposited thin films of various methacrylic copolymers were obtained. We demonstrate reversible photo-induced dimerisation of coumarin moieties within the films. SHG measurements were carried out on two structurally different states of the films, induced by changing the irradiation wavelength. Large SHG modulations of photocross-linkable coumarin-based copolymers are obtained. The quadratic NLO responses appear to be strongly dependent on the (a)

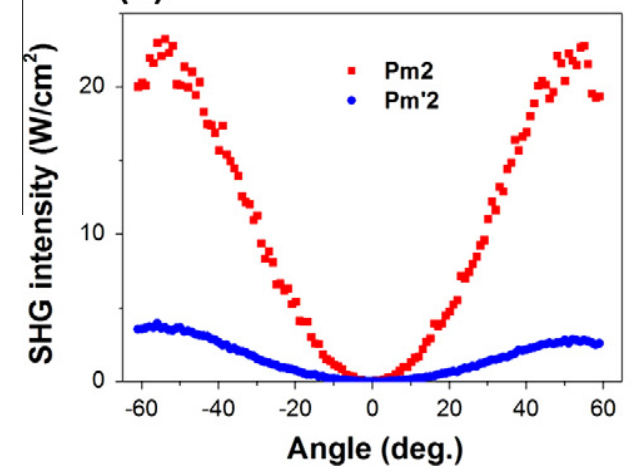

(b)

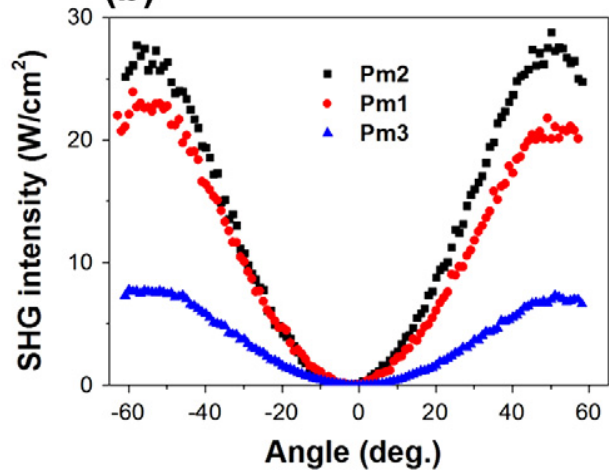

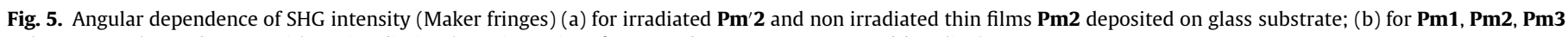
polymers on glass substrate without irradiation (SHG intensity of Pm4 and Pm5 not represented-baseline). 
photo-induced state as the $\chi^{(2)}$ values have been found to be modified up to 2.7 times between the two states.

\section{Acknowledgements}

The authors thank Sandie Pioge (University of Le Mans, Laboratory $\mathrm{UCO}_{2} \mathrm{M}$ ) for Gel Permeation Chromatography as well as Prof. L. Fontaine and Dr. V. Montembault. This work was supported by the Région des Pays de la Loire (Program MoltechAnjou).

\section{References}

[1] C. Samyn, T. Verbiest, A. Persoons, Macromol. Rapid Commun. 21 (2000) 1.

[2] P.N. Prasad, D.J. Williams, Introduction to Nonlinear Optical Effects in Molecules and Polymers, John Wiley, New York, 1991.

[3] P. Che, Y. He, X. Wang, Macromolecules 38 (2005) 8657.

[4] V. Smokal, A. Kolendo, O. Krupka, B. Sahraoui, J. Optoelectron. Adv. Mater. 10 (2008) 607.

[5] K. Ichimura, Chem. Rev. 100 (2000) 1847.

[6] D. Gindre, A. Boeglin, A. Fort, L. Mager, K.D. Dorkenoo, Opt. Exp. 14 (2006) 9896.

[7] Y. Chen, Y. Araki, J. Doyle, A. Strevens, O. Ito, W.J. Blau, Chem. Mater. 17 (2005) 1661.

[8] K. Gnanaguru, N. Ramasubbu, K. Venkatesan, V. Ramamurthy, J. Org. Chem. 50 (1985) 2337.

[9] C. Kim, J.U. Wallace, A. Trajkovska, J.J. Ou, S.H. Chen, Macromolecules 40 (2007) 8924.

[10] J. Moorthy, K. Venkatesan, J. Mater. Chem. 2 (1992) 675.
[11] S. Karthikeyan, V. Ramamurthy, J. Org. Chem. 71 (2006) 6409.

[12] J.N. Moorthy, K. Venkatesan, R.G. Weiss, J. Org. Chem. 57 (1992) 3292

[13] F. Lewis, S. Barancyk, J. Am. Chem. Soc. 111 (1989) 8653.

[14] S. Trenor, A. Shultz, B. Love, T. Long, Chem. Rev. 104 (2004) 3059.

[15] C. Kim, J.U. Wallace, S.H. Chen, P.B. Merkel, Macromolecules 41 (2008) 3075.

[16] Y.Q. Tian, E. Akiyama, Y. Nagase, J. Mater. Chem. 13 (2003) 1253.

[17] S. Fomine, C. Delgado, L. Fomina, R. Gavino, T. Ogawa, Macromol. Chem. Phys. 198 (1997) 3065

[18] G. Jones, M.A. Rahman, J. Phys. Chem. 98 (1994) 13028.

[19] K. Iliopoulos, O. Krupka, D. Gindre, M. Sallé, J. Am. Chem. Soc. 132 (2010) 14343.

[20] M. Obi, S. Morino, K. Ichimura, Chem. Mater. 11 (1999) 656.

[21] P.O. Jackson, M. O'Neill, W.L. Duffy, P. Hindmarsh, S.M. Kelly, G.J. Owen, Chem. Mater. 13 (2001) 694.

[22] F. Kajzar, J.-M. Nunzi, Molecule orientation techniques, in: F. Kajzar, R Reinisch (Eds.), Chapter from Beam Shaping and Control with Nonlinear Optics, Kluwer Academic Publishers, 1998.

[23] M.A. Mortazavi, A. Knoesen, S.T. Kowel, B.G. Higgins, A. Dienes, J. Opt. Soc. Am. B 6 (1989) 733.

[24] B. Kulyk, Z. Essaidi, J. Luc, Z. Sofiani, G. Boudebs, B. Sahraoui, V. Kapustianyk, B. Turko, J. Appl. Phys. 102 (2007) 113113.

[25] J. Jerphagnon, S.K. Kurtz, J. Appl. Phys. 41 (1970) 1667.

[26] N. Tsutsumi, O. Matsumoto, W. Sakai, T. Kiyotsukuri, Macromolecules 29 (1996) 592

[27] S. Malkmus, F.O. Koller, S. Draxler, T.E. Schrader, W.J. Schreier, T. Brust, J.A. DiGirolamo, W.J. Lees, W. Zinth, M. Braun, Adv. Funct. Mater 17 (2007) 3657.

[28] J. Lott, C. Ryan, B. Valle, J.R. Johnson III, D.A. Schiraldi, J. Shan, K.D. Singer, C. Weder, Adv. Mater. 23 (2011) 2425.

[29] D. Gindre, I. Ka, A. Boeglin, A. Fort, K.D. Dorkenoo, Appl. Phys. Lett. 90 (2007) 094103. 